\title{
A EXPERIÊNCIA SUBJETIVA COM A DOENÇA MENTAL O caso da depressão
}

\author{
Cecília Neto \\ Centro de Educação Especial Rainha Dona Leonor (CEERDL), Caldas da Rainha, Portugal \\ Fátima Alves \\ Centro de Estudos das Migrações e das Relações Interculturais (CEMRI), Universidade Aberta, \\ Porto, Portugal
}

\section{Introdução}

AOrganização Mundial de Saúde considera que a depressão crónica é, atualmente, "a principal causa de incapacitação em todo o mundo e ocupa o quarto lugar entre as dez principais causas de patologia" (OMS, 2002: XII). Situação ainda mais expressiva pois estima-se que em 20 anos a depressão crónica venha a ocupar a segunda das principais causas de doenças no mundo. Segundo a OMS, se persistirem as atuais tendências de transição demográfica e epidemiológica até 2020, a taxa da depressão subirá para $5,7 \%$ da carga total de doenças; e em cerca de $20 \%$ dos casos a depressão seguirá um curso crónico, sem remissão (id., ibid.: 69).

Em Portugal, os dados do 4..$^{\circ}$ Inquérito Nacional de Saúde permitem-nos observar que, no conjunto das doenças crónicas, a depressão ocupa a terceira posição (INE e INSA, 2009), representando 8,3\% no Continente, 5,4\% na Região Autónoma dos Açores e 4,1\% na Região Autónoma da Madeira. Neste contexto, a OMS (2002) tem vindo a alertar para os pesados encargos que as perturbações depressivas impõem à sociedade, em termos de sofrimento e incapacidade individual, de disfunção familiar e de diminuição da produtividade no trabalho. Associado à depressão crónica está o grande absentismo profissional que a doença provoca. Consequentemente, as ausências ao trabalho (intermitentes ou prolongadas) conduzem a uma diminuição do rendimento, à redução da produtividade e, muitas vezes, a despedimentos ou reformas antecipadas (Costa e Moniz, 2007).

Face ao número crescente de casos de doenças psiquiátricas, temos vindo a assistir à criação de recursos e de respostas às necessidades colocadas, quer ao nível do atendimento e cuidado psiquiátrico quer ao nível da reabilitação e inserção social. As políticas públicas no domínio da doença mental têm vindo a orientar-se para um modelo organizacional dos serviços assente na comunidade (MS e DGS, 2004). A desinstitucionalização psiquiátrica, tentada sucessivamente desde o final dos anos 60 seguindo as tendências internacionais, por obstáculos variados, só a um ritmo muito lento tem vindo a ser implementada e com graves insuficiências e lacunas no atendimento das necessidades globais desta população (Alves e Silva, 2004; Hespanha, 2010). No Plano Nacional da Saúde Mental da Coordenação Nacional para a Saúde Mental (2008), prevê-se a criação de serviços descentralizados mais próximos das populações. No entanto, o contexto atual de crise generalizada trará certamente novas limitações a 
este setor, sucessivamente negligenciado, vulnerabilizando ainda mais estas populações com doenças mentais crónicas.

O aumento das doenças crónicas, nomeadamente das doenças mentais crónicas, bem como as mudanças operadas no domínio das respostas à doença mental, coloca-nos perante a necessidade de avaliar os seus impactos na vida das pessoas, dos grupos e das organizações sociais, mas também de compreender as vivências, as alterações e ajustamentos que exige ao nível da identidade e dos modos de vida.

Com esta pesquisa procurámos compreender como é que os próprios sujeitos que vivenciam a depressão a entendem, a explicam e interpretam, a introduzem no seu quotidiano e lidam com as suas consequências e impactos nos vários níveis e contextos onde a sua vida decorre. Neste artigo exploraremos as conceções e representações sobre a sua própria doença, evidenciando as tensões entre o passado, vivido como o tempo "normal", e o presente, onde se processa a experimentação subjetiva do novo "eu" e se "reconstrói" a identidade atual.

Os significados sociais associados à doença mental, bem como à depressão, são construções socioculturais espaciotemporalmente determinadas (Kleinman, 1981; Foucault, 1989). Desde os tempos mais remotos e em diferentes culturas, existem descrições sobre a depressão (Vallejo-Nágera, 2006). Trata-se de descrições próximas das conhecidas atualmente, ainda que expressas em linguagem diferente e sujeitas a interpretações distintas (religiosas ou mágicas, ou de tipo científico oficial), de acordo com os critérios da época.

O modelo biomédico da doença lança os fundamentos sobre os quais assenta a medicina ocidental moderna e determina grandemente a configuração dos sistemas de cuidados existentes. Segundo Foucault (2007), o biopoder é uma teia de normas e regras de "domesticação" dos corpos, disciplina que invade e penetra todas as dimensões da vida. A doença é definida "objetivamente", com base em sintomas identificáveis que se enquadram em classificações, cujas causas assentam essencialmente em fatores orgânicos.

Se existe um consenso relativo sobre as funções físicas dos sistemas físicos o mesmo não se verifica em relação aos sistemas implicados no funcionamento psicológico. A definição primária de doença física assenta, essencialmente, em disfunções no corpo, apesar de poder ser relacionada com fatores sociais e culturais. Já a doença mental, tal como Horwitz e Scheid (1999) acentuam, depende não apenas da disfunção mas simultaneamente da consideração da desadequação social e cultural nela implicada. É aqui que reside, desde logo, o interesse da abordagem sociológica.

Por referência às ciências sociais sublinhamos a importância dos domínios cultural e social, e acentuamos a importância de tomar como objeto de análise a perspetiva dos sujeitos que lidam, eles próprios, com a atribuição e vivência de doença mental, com todas as consequências que terá nas suas vidas quotidianas e na sua identidade, tal como Alves (2011) propõe. É pois esta constatação que este estudo exploratório tentou evidenciar. 


\section{A depressão enquanto doença crónica e enquanto desvio social}

Analisar a doença mental a partir da perspetiva das "doenças" designadas "crónicas" coloca-nos perante o desafio de analisar as circunstâncias sociais implícitas na vivência da doença e não apenas o estudo das causas. A análise remete-nos para a compreensão da ação social e da experiência com a depressão. Esta compreensão da depressão enquanto doença crónica configura-se como uma realidade em que intervêm múltiplos níveis de análise (Strauss, 1975; Alves, 2011; Mendes, 2005).

Como refere Strauss (1978 cit. em Mendes, 2005: 46):

os doentes no seu trabalho de gestão da doença [...] têm também que gerir as consequências da doença sobre a sua organização de vida, as suas relações com os outros e até certo ponto a sua relação consigo próprios. Assim, o doente tenta sempre preservar as suas inserções habituais nas diferentes arenas sociais, isto é, ele tenta sempre manter a sua intervenção como ator da construção negociada da doença com novos atores, de forma a fazer face ao impacto desorganizador das doenças crónicas.

Face a estas doenças, a manutenção das obrigações sociais assume especial relevo, já que a doença ao prolongar-se, não pode continuar a ser encarada como uma suspensão temporária do desempenho dos papéis sociais, como acontece face às doenças agudas.

Este tipo de doenças têm vindo a desafiar os sistemas de cuidados disponíveis para com elas lidar, no sentido de minimizar, e de gerir também, os impactos na vida quotidiana. Se, por um lado, procuram controlar a evolução da doença, os seus sintomas e crises, por outro, não podem descurar uma intervenção social com o objetivo de manter alguma qualidade de vida. Aqui o doente, tal como Parsons (1951) analisou, assume um papel mais ativo, pois dele se exige que reconheça os primeiros sinais da crise e procure ajuda. Também se espera que decida em conformidade e com eficácia, nomeadamente adotando comportamentos que previnam o aparecimento de sintomas ou que os consigam gerir de tal forma que estes não dominem a vida do indivíduo, impedindo a vida de acontecer. "Só esta aprendizagem lhe permitirá tomar decisões e, consequentemente, organizar a sua vida face às exigências da doença, ou seja, só isso lhe permitirá gerir a doença" (Mendes, 2005: 44). É este o desafio lançado àqueles que sofrem de doenças crónicas, comoé o caso da depressão.

No entanto, quando falamos em doenças mentais crónicas, há especificidades que não podemos ignorar, pois socialmente os impactos de uma doença mental são bem diferentes dos de uma doença física (Miles, 1982; Alves, 2011). Neste contexto, e tentando compreender a experiência subjetiva do indivíduo em relação à sua própria doença, correlacionando-a com a experiência objetiva (por referência ao diagnóstico psiquiátrico), seus impactos e implicações na reconstrução de si e da própria situação, são de referência obrigatória os contributos da perspetiva interacionista de Goffman (2003 [1961]; 1982 [1963]), com os seus conceitos de "identidade deteriorada", "carreira de doente mental" e "cerimónia de degradação do status". O rótulo psiquiátrico de uma pessoa só se torna significativo na medida em 
que essa interpretação altera o seu destino social - uma alteração que se torna fundamental, sobretudo quando é confrontada com o diagnóstico psiquiátrico de doença mental crónica e passa pela hospitalização. A angústia resultante dessa perceção de si mesmo e as estratégias usadas para a reduzir variam de acordo com a cultura e a pessoa. A atribuição de um diagnóstico psiquiátrico sujeita o indivíduo a um conjunto complexo de experiências de mortificação e reconstrução identitária.

O efeito da temporalidade na trajetória identitária, difícil de observar e operacionalizar mas fundamental para compreender a sua importância no controlo dos indivíduos, na medida em que reflete as imposições culturais, tal como Fox (1999) destacou, contribuirá para a compreensão dos impactos da doença na vida quotidiana. Para Bury (2000 [1997]) o aparecimento da doença, especialmente a que é evidentemente incapacitante, desmembra o tecido social e cultural, expondo o indivíduo às ameaças de self-identity e à perda de controlo, potencialmente prejudicial. O termo de biographical disruption foi cunhado para dar expressão a esses processos (id., ibid.). Desta forma, tratar a experiência subjetiva da doença (illness) como um evento de "disrupção" permite que o seu significado se situe num contexto temporal e na trajetória de vida. O aparecimento dos sintomas, bem como as mudanças no corpo e na mente, os ajustamentos ou desequilíbrios sociais que se lhes seguem, envolvem simultaneamente uma alteração na situação de vida da pessoa e nas suas relações sociais, integrando a doença nos outros tempos da vida quotidiana, que se seguem ao desencadear da crise: o trabalho, as sociabilidades, a família, a cultura.

\section{Metodologia}

Na presente pesquisa privilegiámos uma abordagem das racionalidades leigas enquanto lugar de produção e de reprodução de saberes que visam ordenar o mundo e dar-lhe sentidos, numa ação reflexiva que combina conhecimentos provenientes de várias fontes - sejam da ciência, sejam da tradição (Alves, 2011). No campo da saúde, apesar da centralidade que a medicina ocupa e da sua recusa em partilhar o campo com outros saberes, nomeadamente os leigos, esses saberes coexistem, enquanto modos de produção de sentido (que conferem significados, explicações, estratégias de tratamento e cura, etc.) e de orientação das ações (Lopes, 2003; Carapinheiro, 2007; Silva, 2008, Alves, 2011).

Esta pesquisa adota uma abordagem qualitativa que privilegia o ponto de vista do nativo de Geertz (1993) e se apoia no argumento de pluralidade de habitus e de contextos de ação (Lahire, 2005). Trata-se de um estudo exploratório, onde se destaca o papel ativo do sujeito na construção das suas vivências em torno da depressão crónica. O conhecimento detalhado da pessoa e a sua experiência com a doença permite o acesso aos sentidos e aos significados que o sofrimento e o diagnóstico psiquiátrico trazem ao próprio doente. Foram realizadas entrevistas semiestruturadas, em profundidade, com o objetivo de ter acesso a essa vivência com depressão crónica. O estudo e interpretação da informação recolhida foram efetuados tendo por referência a análise de conteúdo (Bardin, 
1979), partindo das dimensões criadas para a abordagem empírica e estando abertos à riqueza e complexidade que esta realidade nos pudesse revelar.

\section{Os sujeitos entrevistados}

Neste estudo foram cumpridos os requisitos formais de consentimento informado, confidencialidade e anonimato dos participantes, tendo sido pedida autorização formal para a realização das entrevistas que se iniciaram em maio de 2010, tendo passado pelos procedimentos formais que um projeto de investigação deste tipo exige.

Entrevistámos dez homens e mulheres com diagnóstico psiquiátrico de depressão crónica, integrados na comunidade e sinalizados e acompanhados em consulta de Psiquiatria e Saúde Mental no ano de 2010, que se apresentaram disponíveis e aceitaram colaborar. Trata-se de uma amostra não representativa do ponto de vista estatístico, mas que pode ser considerada representativa do ponto de vista sociológico em profundidade, e que procura identificar tipos de situações e compreender as relações sociais que nelas se estabelecem (Lima, 1987).

\section{Resultados}

Os discursos leigos sobre a depressão crónica

Os discursos das pessoas com depressão crónica entrevistadas dão-nos a ver "depressões" em vez de uma classificação homogénea e claramente definida. Em termos gerais classificam-na ora como "doença", ora como "não doença". Estas conceções enraízam-se nos percursos de sofrimento vivenciados e narrados, relacionando-se intimamente com conceções culturalmente fundadas sobre o que sentiam/sentem, os impactos na vida quotidiana, bem como com os itinerários terapêuticos efetuados (estes não serão alvo de análise neste artigo).

O contacto com a psiquiatria permite integrar, numa explicação médica, um conjunto de fatores que "desculpabilizam" o individuo de comportamentos socialmente avaliados como negativos - o que o senso comum classifica como preguiça aparece interpretado como sinal de doença, por exemplo. Por um lado, esta moldura "desculpabiliza" e "desresponsabiliza" o indivíduo e tem reflexos positivos na identidade. Por outro lado é instaurado o rótulo biomédico de doente mental que desencadeia processos estigmatizantes com consequências identitárias e sociais devastadoras. Estes são recusados, o que sem dúvida instaura uma dualidade ambivalente que conduz à distinção entre ter uma depressão e uma doença mental. Nos discursos, a depressão vista como sofrimento mental não é considerada uma "verdadeira" doença mental. Esta depressão é algo mais "leve" e menos carregado simbolicamente.

\section{As conceções}

Não encontrámos nesta pesquisa conceções claramente definidas e homogéneas. Pelo contrário, deparámos com uma pluralidade de conceções intra e intersujeitos 
entrevistados. Muito poucos são os que se referem ao seu sofrimento com sendo uma depressão, e mesmo nestes casos referem-se utilizando expressões como "e agora quando eu estou assim com a tal depressão", "descolando-a" da sua identidade pessoal. A maioria refere não saber o seu diagnóstico ou que, quando lhe falaram em depressão, não sabiam o que era. Descrevem o seu sofrimento por referência ao que sentiram/sentem, adotando denominações mais ligadas a uma conceção cultural e contextual, como por exemplo: "esgotamento", "vontade de morrer", "stresse", "fraqueza", "nervoso" ou "dos nervos", "desequilíbrio no ritmo do sono", etc.

A conceção subjacente à ideia de depressão enquanto doença (muitas vezes porque diagnosticada pelo médico) inclui o sofrimento vivido numa perceção que acentua a gravidade da situação, algo ameaçador da vida em sociedade e da identidade. Aqui o sofrimento é entendido, geralmente, como não tendo cura (sendo crónica), e causa do mal-estar (no sentido oposto ao de bem-estar e felicidade). Este mal-estar, pela sua intensidade e duração, refere-se essencialmente aos afetos (negatividade do que se sente) e às suas consequências: rejeição/desilusão familiar, vergonha, isolamento social, medo do futuro, entre outras.

Nesta conceção enquanto doença, a depressão é vista como incapacitante, pois considera-se que a pessoa fica enfraquecida, sem forças, lenta, cansada, com as suas capacidades de raciocínio e decisão diminuídas, com as suas possibilidades de vida comprometidas, características que se situam entre a doença (enquanto algo exterior) e a vida real. Metaforicamente, falam no "buraco" em que a pessoa entra e na ausência de "luz no fundo do túnel".

Quando se referem ao "antes do surgimento da doença" falam em "quando eu era uma pessoa normal". Este critério de "normalidade" refere-se sobretudo às capacidades relacionadas com o desempenho dos papéis sociais em adultos (trabalhador/a, pai/mãe, filho/filha, irmão/irmã, amigo/a, etc.).

Para mim a depressão que é aquilo que eu sinto: é uma tristeza... uma tristeza que não sai... é crónica [...] falando por mim... eu era uma pessoa muito alegre [...] Os meus filhos não se lembram... ou por outra... não conheceram a outra mãe que têm... [Fem04, 49 anos, 6. ano, reformada]

O maior receio que apresentam é o de poderem vir a tornar-se malucas/os, o que sem dúvida reflete o estigma social associado à "verdadeira doença mental". Este receio manifesta-se no medo de ficar sem memória (por referência ao cérebro e à cabeça, estruturante dos discursos em torno da doença mental em geral) e de perder a noção da realidade, numa explicação que simultaneamente afasta o rótulo de doença mental para o seu caso (que é sentido como diferente desta), e afirma a natureza "mais leve" da depressão que se vive e que, apesar de crónica e incurável, aparece nos discursos muito mais relacionada com a vivência e os afetos que resultam de reações a situações de vida, e não como algo endógeno, biológico, interno, constitucional.

Não sei... [...] Às doenças de nervos [...] Há umas melhores e outras piores [...] É intermédia. Porque há medicação, mas não há cura. [Masc09, 60 anos, 1.ํㅜㄹo, empregado] 
Estamos em presença de duas perceções bem diferenciadas de doença mental: a que aparece relacionada com o organismo, com o cérebro, com os "nervos", e uma perturbação do tipo psicossocial, relacional, ligada aos acontecimentos de vida e à personalidade do indivíduo por referência à relação entre o indivíduo e a sociedade.

Está relacionada com o pensamento. Antes achava que tinha a ver com o cérebro. Eram aquelas pessoas que não estavam boas da cabeça, estavam doidas. Associava às camisas de força e aquelas intuições... [...] aos hospitais... [Mas07, 27 anos, ensino superior, desempregado]

Esta pluralidade conceptual e complexidade explicativa da situação aparecem também associadas ao sentimento de incompreensão face à sua situação. Sentem-se incompreendidos e incapazes de transmitirem o que sentem ou vivem àqueles que os rodeiam nas suas várias áreas de vida. Esse sentimento aparece refletido na observação das atitudes dos outros face à situação - referem que as pessoas estranham e não sabem como agir em relação a eles. Por vezes não há comportamentos exteriores denunciadores da doença, que aparece "mascarada" ou encoberta, de modo que os outros até podem perceber algo estranho, mas não reconhecível enquanto depressão. O que leva a que muitos não reconheçam a doença ao doente, não os compreendam, desvalorizem o seu sofrimento atribuindo-o a falhas de caráter, de personalidade, culturalmente reprováveis e depreciativas da pessoa. Por um lado, recusam o rótulo pelas consequências na identidade social e, por outro lado, reclamam-no enquanto condição de compreensão da sua situação, explicada pela doença e não pela falta de competência social e cultural.

O estado de alma... podemos dizer que é a emoção [...] O que é que eu sinto, ou o que é que é estar deprimido... Por exemplo, eu tenho muitas depressões. Eu tenho uma depressão que é do tipo mascarada. Significa que não aparento estar deprimida, mas estou... Podem-me achar estranha mas não sabem que eu estou deprimida... [Fem02, 44 anos, ensino superior, empregada]

Encontrámos também a referência ao sofrimento que se relaciona com a forma de ser da pessoa, com o "feitio", e que condiciona a sua vivência quotidiana, aparecendo nos discursos como sendo ansiedade, fraqueza, tristeza crónica, nervos, pensar muito, medos variados e incapacitantes da ação. Distinta contudo da verdadeira doença.

Penso e pergunto-me a mim mesma: "Porque raio eu tenho este feitio... porque é que eu sou assim..." [...] Eu é que penso que é o feitio... mas é a maneira de ser da pessoa [...] mas não sei dar explicação para isso... [...] Eu gostava muito de ser de outra maneira... não queria ser assim como sou... [Fem03, 49 anos, 6. ${ }^{\circ}$ ano, reformada]

O desinteresse generalizado aparece nos discursos como explicativo do descuido pela imagem pessoal (aparência, peso, etc.), do desinteresse pelo cuidado das 
atividades de casa, etc. A tristeza constante que referem sentir, manifesta no choro sem motivo, na lentificação ou agitação motora e psicológica, no desinteresse social e relacional, na alteração do ritmo do sono (ou não conseguem dormir ou dormem todo o tempo), permite que se instale um sentimento de incapacidade generalizado. As pessoas deixam de ter uma vida "normal", no sentido do desempenho dos papéis sociais e das funções que lhes estavam atribuídas. O sentimento de incapacidade que daí resulta reforça o imobilismo da ação. Refugiam-se do mundo, de onde referem muitas vezes ter vontade de desaparecer - quer no sentido de deixar de existir, quer no sentido de começar de novo, com outra vida e outras oportunidades para vencer o sofrimento.

\section{Causalidade da depressão}

O domínio da causalidade do adoecer, do ponto de vista dos discursos leigos, tem vindo a ser estudado no campo das ciências sociais e os que encontramos neste trabalho deles não se afastam: elementos do domínio do sobrenatural, do social, do natural e do próprio doente (Nunes, 1997; Alves, 2011).

Como é que os sujeitos explicam as razões do surgimento do seu sofrimento? Os sistemas explicativos causais encontrados não são monolíticos nem exclusivos - muitas vezes faz-se uso de vários elementos, combinando-os numa explicação singular dos acontecimentos e das trajetórias de cada um. É precisamente esse percurso "entre elementos" que nos deixa perceber melhor as conceções e o quadro explicativo sobre cada sofrimento relatado.

Constatamos que neste grupo de entrevistados a depressão ou o sofrimento que relatam são explicados por relação com uma situação ou a um acontecimento doloroso. Esta experiência humana é provocada, na maior parte dos discursos analisados, pelas realidades quotidianas: as inevitáveis infelicidades da existência.

Apesar de termos encontrado alguns discursos em que o desconhecimento das causas é afirmado, ao longo das entrevistas pudemos perceber a necessidade que sentem de encontrar uma explicação para o seu caso, interrogando as razões que poderão dar sentido ao sofrimento. De um modo geral, encontrámos os seguintes elementos causais explicativos do surgimento do sofrimento vivenciado: elementos hereditários, sociais, económicos, culturais e elementos característicos da personalidade individual.

Nos elementos hereditários, por exemplo, são referidas as situações de sofrimentos semelhantes em familiares próximos em quem identificam traços da personalidade, acentuando a "herança" cultural (de formas de ser, de se comportar, de se relacionar) ou orgânicos (o "sangue" de família como forma de transmissão do sofrimento). Quer num caso quer no outro este sistema de causalidade alivia o indivíduo da responsabilização pelo seu sofrimento.

Exatamente, a minha depressão é hereditária. É por isso que ela começa tão jovem...e é claro que também é formada por um ambiente familiar... triste, pesado, [...] um pai que está sempre doente. [...] [Fem02, 44 anos, ensino superior, empregada] 
Os elementos que colocam em evidência a relação do sujeito com a sociedade e o habitus construído para explicar o sofrimento, e que neste trabalho designamos como sociais, são variados. Maioritariamente são referidos os relacionamentos (inconsistência da personalidade dos progenitores, maus-tratos psicológicos entre cônjuges, sobrecarga familiar, etc.). Ao nível das relações interpessoais acentuam a instabilidade das relações afetivas (o desgosto e deceção, situações de "traição" pelos amigos), que muitas vezes se transforma em incapacidade relacional. É com base nestas causalidades que os sujeitos entrevistados remetem o seu sofrimento para um estatuto de "não doença", justificando-o com base em situações e acontecimentos de vida "normais" (no sentido em que é comum ao longo do ciclo de vida confrontar-se com eles), geralmente problemáticos. Expressões como "esgotamento", "nervos" e "stresse" são comuns para definir o sofrimento de que padecem.

Sim... ah... dizem... a minha mãe tenta fazer algo... o meu pai é uma pessoa muito distante e foi sempre muito frio desde eu em pequeno... [...] Frio é... não transmitir sentimentos e nunca me valorizou... [Masc07, 27 anos, ensino superior, desempregado]

As explicações causais que assentam em fatores económicos acentuam situações variadas que se relacionam com o endividamento e a incapacidade de consumir de acordo com os padrões sociais (a sociedade de consumo em que vivemos que leva as pessoas a sentir necessidades que não tinham, instalando-se o vazio e a angústia quando não podem satisfazê-las).

[...] O meu problema partiu, vamos considerar... foi um fio podre que surgiu na nossa vida... foi um empenhamento monetário... de uma situação que perdi o controlo... isto ficou mesmo descontrolado [...] [Mas08, 49 anos, 9.ำ ano, empregado]

Os elementos situados na própria pessoa ou característicos da personalidade individual são evocados sobretudo para encontrar sentidos para o sofrimento e explicar a sua instalação/cronicidade. A ideia de que o "feitio" causa ou favorece este tipo de sofrimento fica patente em alguns discursos. É ele que torna umas pessoas "mais fracas" do que outras e suscetíveis de virem a sofrer psicologicamente (mais do que socialmente e culturalmente esperado) com os acontecimentos da vida quotidiana.

[...] Penso e pergunto-me a mim mesma: "Porque raio eu tenho este feitio... porque é que eu sou assim..." [...] Eu é que penso que é o feitio... mas é a maneira de ser da pessoa.

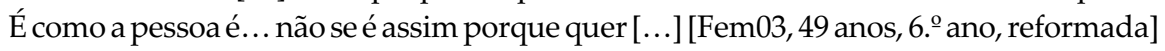

O antes e o depois da doença: tensões entre a normalidade e a experiência subjetiva do novo "eu"

As conceções sobre a sua situação, resultantes da negociação entre os sujeitos, as instituições, os profissionais e a sociedade onde vivem, permitem-nos ter acesso às tensões entre a situação de vida passada e a experimentação subjetiva do novo "eu" que se constrói em torno da situação de sofrimento vivenciada. Esta vivência do 
sofrimento e a atribuição do diagnóstico provocam impactos sociais com consequências nos percursos de vida que se estendem à identidade. As repercussões na evolução da doença e no seu enfrentamento são uma realidade. Sobretudo, ao nível das redes sociais que diminuem, resultado do isolamento social, mas também ao nível da grande apreensão e medo de encarar o futuro.

As mudanças resultantes da doença são complexas e multidimensionais, convocando na sua explicitação os níveis familiar, dos amigos, trabalho, lazer, saúde física e identidade.

Ao nível dos relacionamentos interpessoais constatam a diminuição das redes de sociabilidade resultantes do isolamento a que se submetem, ora porque ficam desconfiados das palavras que são ditas e dos atos que são praticados pelos outros, ora porque os protegem do seu sofrimento e da sua negatividade. Neste contexto, o surgimento da depressão relega a pessoa para o isolamento e encerramento sobre si próprio (onde encontra solidão, sossego, quietude) recusando e recusando-se o convívio social. A desmotivação estende-se às atividades de lazer e tempos livres que abandonaram.

A falta de compreensão que dizem sentir é atribuída ao facto de os próprios não conseguirem explicar o que sentem e do que sofrem, sendo muitas vezes mal interpretados os sinais que apresentam. Por analogia com a doença física sentem que o seu sofrimento não é digno de crédito, pois não o podem provar ou demonstrar fisicamente. Muitas vezes sentem até que a família os ignora ou atua de propósito para agravar os sinais de sofrimento, de tal forma é o descrédito que dizem sentir. O abandono a que se sentem votados marca os discursos. Este descrédito e abandono são referidos como agravante do sofrimento que vivenciam. A necessidade de compreensão é explicitada na medida em que desejariam ter alguém em quem pudessem confiar, com quem desabafar, conversar.

E por vezes é uma doença muito chata... porque por vezes as pessoas não acreditam... porque como não é uma doença que se veja... não se sabe dar o valor àquilo que a gente está a padecer... [ Fem03, 49 anos, $6 .{ }^{\circ}$ ano, reformada]

[...] convidar-me para sair... será que eu faço bem, ou será que faço mal em ir... Quando [...] não me convidam eu penso: não me convidaram porque a culpa é minha... eu é que estou assim [...] é o tal ciclo vicioso [...] [Mas07, 27 anos, ensino superior, desempregado]

[...] Ser compreendido e ter alguém com quem pudesse falar, conversar... desabafar... alguém que pudesse confiar... Tinha... tinha muita gente... mas agora ... não tenho ninguém [...] [Masc01, 64 anos, 6. ${ }^{\circ}$ ano, empregado]

Poucos são os que se sentem apoiados pela família nuclear. Aí referem a importância do carinho que recebem, bem como da atenção de que são alvo, que ajuda a esquecer o sofrimento e a recuperar. Mas é no seio da família que surgem, em primeiro lugar, as narrativas sobre situações de discriminação e de estigmatização, estendendo-se, de seguida, à própria sociedade. 
[...] quando eu me queixo à minha mulher... ele responde-me logo que eu sou maluco... que eu não tenho nada e que eu tenho que enfrentar as coisas como elas são e deixar-me destas coisas. [Masc09, 60 anos, 1. ${ }^{\circ}$ ciclo, empregado]

São também referidas as relações do casal. A falta de paciência para um relacionamento mais íntimo traduz-se num discurso sobre a indiferença afetiva e o abandono. O impacto do sofrimento nos filhos é referido como muito angustiante.

Uma das consequências mais visíveis deste sofrimento opera-se ao nível laboral ou de empregabilidade. Neste contexto a incapacidade para o trabalho, que dizem sentir, decorre do sofrimento em si, mas também da medicação. Os que se encontram de baixa médica (a receber subsídio de doença) referem sentir-se incapazes de trabalhar pelo facto de isso exigir competências de concentração, memória e rotina, áreas onde apresentam grandes dificuldades. Também é referida a pressão de que se sentem alvo ao nível das relações laborais, sobretudo nos casos em que há conhecimento da situação. Em termos laborais sentem-se discriminados e marginalizados, pois o estereótipo de que não são válidos para o trabalho, resultado da doença, acaba por se manifestar e criar situações que são vividas como injustas. Consequentemente, desenvolvem-se estratégias de ocultação e encobrimento da doença ou do sofrimento, de modo a que se evitem processos de estigmatização que são vividos com grande angústia e violência simbólica, tal como Goffman (1982 [1963]) já tinha analisado. Todos estes fatores são vistos como potenciais promotores de uma recaída. Falam em diminuição da produtividade e, simultaneamente, em alívio por não terem que ir trabalhar.

Digamos que não reúno os requisitos [... ... sinto que não estou apto... eu neste momento não me sinto capaz de desempenhar as minhas funções... [...] tenho muito medo de não conseguir desempenhar as tarefas... [Masc08, 49 anos, 9.. ano, empregado]

A reforma por invalidez acaba por ser a solução encontrada institucionalmente para a situação de alguns dos entrevistados, com todas as consequências sociais e identitárias que acarreta.

E a partir daí nunca mais deixei de sentir os problemas... e até no próprio trabalho começaram as discriminações [...] atiraram-me abaixo, fizeram-me reconversões na carreira... [Masc09, 60 anos, 4..$^{\circ}$ ano, empregado]

É ao nível da identidade e do autoconceito que os discursos centram os impactos, num quadro onde se reequacionam os sentidos da vida e se expõe a falta de esperança em que tudo volte a ser como era antes do surgimento da doença, destacando o efeito da temporalidade e a consequente mudança biográfica. Observámos o sentimento generalizado de que a pessoa deixou de ser ela própria, não se reconhece mais naquilo que agora é, sente vergonha do que é e autoperceciona-se como não tendo futuro. Os discursos revelam sistematicamente desesperança, desistência, ideias de suicídio. Esta "destruição identitária" e consequente "mortificação do 
eu" resulta do sentimento de não ter valor nem utilidade social - sentem-se desvalorizados pelos outros e, consequentemente, incarnam e reproduzem a inutilidade, sentindo-se eles próprios inúteis e sem valor, num ciclo que reproduz a situação.

[...] e depois é como autocastigar-me... é andar sempre com aqueles pensamentos: não vales nada... ou... não tens valor... sentir-me inútil... pronto... [Mas07, 27 anos, ensino superior, desempregado]

[...] tenho medo de ficar maluca, não saber aquilo que diz ou que faz... [Fem03, 49 anos, 6. ${ }^{\mathrm{o}}$ ano, reformada]

[...] a atitude que eu tenho até agora é de ocultar, não dar a conhecer, para não ser estigmatizada... [Fem02, 44 anos, ensino superior, empregada]

É reconhecida a incapacidade que a doença introduz na pessoa porque "não consigo encarar o dia, não consigo encarar a vida". Encaram o futuro com grande apreensão e descrença, pois o sofrimento continua, os medicamentos não curam e sentem que nada mudará. A possibilidade de virem a ter vidas "normais" é posta de parte, o que causa grande sofrimento e reforça a situação que vivenciam. O medo do abandono pelos que ainda estão próximos, ou de ficar "verdadeiramente maluco", conduz ao imobilismo, à inação, num círculo que se encerra novamente sobre si próprio, sem esperança no futuro: "deitar-se na cama e ficar ali até morrer, sem comer".

Ansiedade, grande descontrolo... Tive duas tentativas de suicídio. [Mas08, 49 anos, 9.․o ano, empregado]

A família dela também não aparece... toda a gente sempre me pôs de parte... devo sofrer de um mal muito grande que as pessoas têm medo de se aproximarem e contagia-

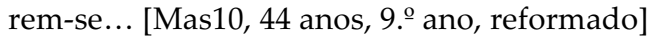

As representações de si e da situação refletem a temporalidade, a conceção da doença e do sofrimento em termos das suas dimensões históricas e das diferentes fases do curso da vida do indivíduo, ou biografia. Com a temporalidade procurámos os significados simbólicos do sofrimento e as expetativas dos entrevistados face ao futuro, construídas a partir do impacto do diagnóstico psiquiátrico de doença mental na experiência com a doença. Dedicámos especial atenção aos seguintes tempos e momentos-chave: "antes do surgimento do sofrimento", "o momento do surgimento do sofrimento", o de "diagnóstico", sua "evolução posterior" e, por fim, a sua "projeção no futuro".

O surgimento dos sintomas e o contacto com o diagnóstico psiquiátrico são momentos decisivos para o processo de "disrupção biográfica" que desencadeia, expondo o indivíduo à perda de controlo e à "mortificação do eu", desencadeando alterações na vida da pessoa e nas suas relações sociais. Essas alterações conduzem ao gradual desaparecimento da pessoa tal como se entendia antes da doença e à 
manifestação das limitações com que se depara no desempenho das tarefas e papéis sociais. O isolamento e o "...medo de ficar louco e de me tornar um peso" é uma estratégia para lidar com a situação. Este contexto de angústia e de desesperança conduzem, em casos limite, ao desejo de acabar com a própria vida suicídio.

Este percurso identitário de passagem de "pessoa" a "doente mental" pode ser realizado através de uma série de estádios interligados. Cada estádio tende a provocar um brusco declínio no "status de adulto livre". Logo que a pessoa é vista como tendo perdido a razão, a sua imagem anterior dilui-se. Deste modo, os indivíduos são "despidos" e desapossados das suas identidades anteriores, e uma nova identidade é construída, o que Goffman (1982 [1963]) denominou "cerimónia de degradação do status". No momento em que se percebe a existência da doença mental e esta é entendida enquanto desvio, reproduz-se, na ação coletiva e nos processos sociais desencadeados, o entendimento pelo qual um indivíduo ou um grupo é considerado desviante pelos demais (Rogers e Pilgrim, 1999).

A média de tempo em acompanhamento na especialidade de psiquiatria dos sujeitos entrevistados ( 21 anos para as mulheres e 10 anos no caso dos homens) e o longo tempo que referem viver com este sofrimento condicionam a ação, na medida em que o associam ao sofrimento que "...vai e vem, mas que não passa", impondo-se uma (re)construção de si em que se destaca a fixação do estatuto de doente para toda a vida, uma vez que "... a psiquiatria e a medicação tratam, mas não curam..."

A persistência do sofrimento durante toda a vida conduz à necessidade de gerir não apenas a doença, sua evolução e suas manifestações, mas também os sentimentos que desencadeia - medo que esta venha a piorar e a transformar-se em loucura, medo de perder autonomia e liberdade e ficar dependente.

Esta gestão quotidiana da doença absorve o indivíduo e cristaliza-o no presente sem futuro e na vivência nostálgica da pessoa que já foi.

[...] É não haver futuro, não sinto perspetivas de futuro, não ter projetos, as pessoas da minha idade trabalham, casaram, tiveram filhos. E eu... [Fem02, 44 anos, ensino superior, empregada]

Eu tenho medo de ficar completamente dependente... de tão nova... [...] Sei lá... a minha cabeça... eu tenho medo... ainda mais do que com o corpo, tenho medo que a minha cabeça vá daqui, deste lado, para o outro... [Fem04, 49 anos, 6. ${ }^{\text {a }}$ classe, reformada]

Poucos são os sujeitos que referem uma perspetiva otimista, assente na confiança que depositam nos profissionais por quem são acompanhados ou de evolução da ciência para encontrar outras respostas para o sofrimento mental. No entanto, a expetativa de construir relações afetivas estáveis é entendida como chave para o alívio do sofrimento. 


\section{Síntese conclusiva}

Esta pesquisa contribui para a compreensão dos significados associados à vivência com a depressão crónica, evidenciando a sua construção social entre os sujeitos e as estruturas sociais, e revela a complexidade dos saberes que enformam estas construções e experiências, que se manifestam reflexivamente ao nível das conceções, interpretações e na ação prática quotidiana. Neste sentido, enriquece os trabalhos prévios na medida em que os seus resultados aprofundam a compreensão da experiência com depressão crónica do ponto de vista dos sujeitos que a vivenciam no quotidiano. Trata-se de uma pesquisa inovadora, em particular no contexto português, que vem apoiar e aprofundar algumas dimensões de trabalhos sociológicos anteriores sobre doença mental (Alves e Silva 2002; Amaro, 2005; Alves, 2011; 2012).

A análise dos discursos suscitados pela entrevista aos participantes deste estudo sobre o domínio da vivência com depressão crónica e seus impactos na vida quotidiana revela e expõe as conceções, complexas e plurais, que se constroem entre as explicações dos profissionais, o habitus, a reação dos outros e a agência individual. A reflexividade que orienta a ação quotidiana em torno da necessidade de lidar com o sofrimento mental, que vai e vem como se fosse um ioiô, em movimentos permanentes, mas nunca iguais, está cheia de ambiguidades e dissonâncias que se articulam com os valores, as normas, a cultura, que moldam o social e se impõem no quotidiano, no tracejar dos percursos terapêuticos e na permanente reconstrução de si.

Por um lado, o sofrimento que vivenciam é visto pelos próprios enquanto algo que não é uma verdadeira doença mental. Essa classificação está reservada para aqueles que "verdadeiramente" perderam a razão e a consciência da realidade, e são destituídos social e culturalmente. A depressão enquanto doença mental desencadeia poderosos processos de "mortificação do eu" e reconstrução biográfica, tal como Goffman (2003 [1961]) já tinha evidenciado. Afastam-se dela, dado o estigma e o seu poder avassalador de destruição identitária, o que já tinha sido observado em outros estudos sobre a realidade portuguesa (Alves, 2011).

Partindo de sujeitos diagnosticados com depressão, esta pesquisa não se circunscreve à aparente homogeneização que a classificação biomédica introduz, nem à sua mera relação com os fatores sociais que nela estão implicados. Os nossos resultados evidenciam não apenas os fatores sociais convocados na carreira do sujeito rotulado, mas também os processos plurais subjacentes à vivência com a depressão crónica. Neste sentido, foram identificados os processos complexos subjacentes ao acesso ao papel de doente, às suas vantagens, tal como Parsons (1951) enaltecera, ou à sua recusa pelas desvantagens implicadas, nomeadamente os seus impactos identitários, resultantes da gravidade da situação e do seu caráter estigmatizante, tal como Freidson (1984 [1970]) já havia assinalado, introduzindo a noção de papéis de doente no plural, para chamar a atenção para a diversidade de condições e vivências. Pudemos compreender que a vivência com depressão está impregnada de complexidades que urge compreender. Vimos que, apesar de os sujeitos entrevistados nunca se identificarem como doentes mentais, e muitos deles utilizarem denominações mais "doces" para se referirem ao seu sofrimento, muitas vezes, face à 
incompreensão social que atribuem ao não reconhecimento do seu sofrimento, requerem a classificação de doença, mas como algo semelhante à doença física, reclamando assim o estatuto social de doente pelo poder de reconhecimento, aceitação e justificação desse sofrimento, bem como das suas consequências sociais e pessoais.

A perceção e vivência do sofrimento, que não é doença mental, apesar de ter subjacente um questionamento do eu, menos pesado, mas exigente do ponto de vista da reconstrução identitária, é mais tolerável pessoalmente, mesmo sentindo-o como algo permanente e sem cura. Este sofrimento é visto como não compreensível socialmente, pois confunde-se com comportamentos socialmente avaliados à luz da moral e dos valores socioculturais e não da instituição médica são vistos como preguiçosos, "cismáticos", complicados, fracos, nervosos, categorias já encontradas no estudo de Alves (2011) e em outros estudos (Miles, 1982; Rabelo, 1999). A falta de vontade e desmotivação generalizada que atribuem à depressão e que não conseguem provar como característica intrínseca desta, e não da pessoa que são, reforça a ideia de incompetência social, relacional e laboral.

É ao nível da identidade e do autoconceito que os discursos centram os impactos, num quadro onde se reequacionam os sentidos da vida e se expõe a falta de esperança em que tudo volte a ser como era antes do surgimento da doença, destacando o efeito da temporalidade e a consequente reconstrução biográfica, tal como Bury (2000 [1997]) destacou. Esta "destruição identitária" e consequente "mortificação do eu", encontradas também por Goffman nos seus estudos, resulta do sentimento de não ter valor nem utilidade social - sentem-se desvalorizados pelos outros e, consequentemente, incarnam e reproduzem a inutilidade, sentindo-se eles próprios inúteis e sem valor, num ciclo que reproduz a situação.

$\mathrm{Na}$ tentativa de lidar com as suas consequências na vida quotidiana, sobretudo ao nível do estigma, a depressão crónica é muitas vezes compreendida como uma das doenças mentais mais aceitáveis, não deixando contudo de estar associada a um futuro negativista ligado à incerteza e ao medo da perda de controlo sobre o indivíduo e sobre a vida - o medo de enlouquecer e de perder a noção da realidade está presente, como uma ameaça que lembra a perda da autonomia e liberdade, e acentua os receios da dependência do suporte social e o medo do futuro, lembrando continuamente que as consequências parecem ser mais devastadoras do que o sofrimento.

\section{Referências bibliográficas}

Alves, Fátima (2011), A Doença Mental nem Sempre é Doença. Racionalidades Leigas sobre Saúde e Doença Mental, Porto, Edições Afrontamento.

Alves, Fátima (2012), “Recognising madness in others; relativising madness in oneself from lay concepts to therapeutic itineraries", em Fátima Alves, Katrina Jaworski e Stephen Butler (orgs.), Madness in Plural Contexts. Crossing Borders, Linking Knowledge, e-book, Oxford, Inter-Disciplinary Press.

Alves, Fátima, e Luísa Ferreira da Silva (2002), “A família como suporte das políticas de saúde mental em Portugal", Actas do VI Congresso Luso-Afro-Brasileiro em Ciências Sociais, FLUP, pp. 95-99. 
Alves, Fátima, e Luísa Ferreira da Silva (2004), "Psiquiatria e comunidade: elementos de reflexão", Actas dos Ateliers do V Congresso Português de Sociologia. Sociedades Contemporâneas. Reflexividade e Acção - Atelier Saúde, Braga, Associação Portuguesa de Sociologia.

Amaro, Fausto (2005), Factores Sociais e Culturais da Esquizofrenia, Lisboa, Instituto Superior de Ciências Sociais e Políticas.

Bardin, Laurence (1979), Análise de Conteúdo, Lisboa, Edições 70.

Bury, Michael (2000 [1997]), Health and Illness in a Changing Society, Londres e Nova Iorque, Routledge.

Carapinheiro, Graça (2007), "Saúde e risco na sociedade portuguesa: para uma nova agenda das políticas da vida", em José Manuel Leite Viegas, Helena Carreiras e Andrés Malamud (orgs.), Instituições e Política, vol. I: Portugal no Contexto Europeu, Oeiras, Celta Editora, pp. 189-201.

Coordenação Nacional para a Saúde Mental (2008), Plano Nacional da Saúde Mental 2007-2016, Lisboa, Ministério da Saúde.

Costa, Ana Luísa, e Almeida Matos Godinho Cardoso Moniz (2007), Depressão e Factores Cronobiológicos, Braga, Universidade do Minho, Instituto de Educação e Psicologia, tese de doutoramento em Psicologia Clínica.

Foucault, Michel (1989), História da Loucura, São Paulo, Editora Perspectiva.

Foucault, Michel (2007), História da Sexualidade, vol. 1: A Vontade de Saber, Rio de Janeiro, Graal.

Fox, Nick J. (1999), “Os tempos dos cuidados de saúde, poder, controlo e resistência”, Sociologia, Problemas e Práticas, 29, pp. 9-29.

Freidson, Eliot (1984 [1970]), La Profession Médicale, Paris, Payot.

Geertz, Clifford (1993), The Interpretation of Culture, Londres, Fontana Press.

Goffman, Erving (1982 [1963]), Estigma. Notas Sobre a Manipulação da Identidade Deteriorada, Rio de Janeiro, Livros Técnicos e Científicos Editora.

Goffman, Erving (2003 [1961]), Manicômios, Prisões e Conventos, São Paulo, Editora Perspectiva.

Hespanha, Pedro (2010), "A reforma psiquiátrica em Portugal: desafios e impasses", em Breno Fontes e Eliane Fonte (orgs.), Desinstitucionalização, Redes Sociais e Saúde Mental. Análise de Experiências da Reforma Psiquiátrica em Angola, Brasil e Portugal, Recife, Editora Universitária UFPE, pp. 25-69.

Horwitz, Allan V., e Teresa L. Scheid (orgs.) (1999), A Handbook for the Study of Mental Health. Social Contexts, Theories, and Systems, Cambridge, Cambridge University Press.

INE, Instituto Nacional de Estatística, e INSA, Instituto Nacional de Saúde Doutor Ricardo Jorge (2009), Inquérito Nacional de Saúde, 2005/2006, Lisboa, INSA/INE, http://www.insa.pt/sites/INSA/Portugues/Publicacoes/Outros/Documents/Epidemi ologia/INS_05_06.pdf (consultado em 23/10/2012).

Kleinman, Arthur (1981), Patients and Healers in the Context of Culture. An Exploration of the Borderland between Anthropology, Medicine, and Psychiatry, Berkeley, Los Angeles e Londres, University of California Press.

Lahire, Bernard (2005), "Patrimónios individuais de disposições: para uma sociologia à escala individual", Sociologia, Problemas e Práticas, 49, pp. 11-42. 
Lima, Marinús Pires de (1987), Inquérito Sociológico. Problemas de Metodologia, Lisboa, Editorial Presença.

Lopes, Noémia M. (2003), Automedicação. Práticas e Racionalidades Sociais, Lisboa, ISCTE, tese de doutoramento.

Mendes, Felismina (2005), “Doenças crónicas: a prioridade de gerir a doença e negociar os cuidados", Pensar Enfermagem, 9 (1), pp. 42-47.

Miles, Agnes (1982), O Doente Mental na Sociedade Contemporânea. Introdução Sociológica, Rio de Janeiro, Jorge Zahar Editor.

MS, Ministério da Saúde, Rede de Referenciação de Psiquiatria e Saúde Mental, Lisboa, Direção-Geral da Saúde, disponível em: http://www.dgs.pt/upload/membro.id/ficheiros/i007439.pdf (consultado a 23/10/2012).

Nunes, Berta (1997), O Saber Médico do Povo, Lisboa, Fim de Século Edições.

OMS, Organização Mundial da Saúde (2002), Relatório Mundial de Saúde. Saúde Mental, Nova Concepção, Nova Esperança, Lisboa, Direção-Geral da Saúde / OMS, http://www.who.int/whr/2001/en/whr01_po.pdf (consultado em 12/9/2012).

Parsons, Talcott (1951), The Social System, Nova Iorque, The Free Press.

Rabelo, Miriam C. M. (1999), “Narrando a doença no nordeste de Amaralina: relatos como realizações práticas", em M. C. M. Rabelo, P. C. B. Alves e I. M. A. Souza, Experiência de Doença e Narrativa, Rio de Janeiro, Editora Fio Cruz, pp. 75-88.

Rogers, Anne, e David Pilgrim (1999), A Sociology of Mental Health and Illness, Berkshire, UK, Open University Press.

Silva, Luísa Ferreira da (2008), Saber Prático de Saúde. As Lógicas do Saudável no Quotidiano, Porto, Edições Afrontamento.

Strauss, Anselm L. (1975), Chronic Illness and the Quality of Life, St. Louis, C. V. Mosby Company.

Vallejo-Nágera, Juan António (2006). A Depressão. Como Lidar com a Doença do Nosso Tempo, Estoril, Princípia Editora.

Cecília Neto. Mestre em Sociologia da Saúde e da Doença (ISCTE/IUL), Centro de Educação Especial Rainha Dona Leonor (CEERDL). E-mail: c-neto@sapo.pt

Fátima Alves. Doutorada em Sociologia, Centro de Estudos das Migrações e das Relações Interculturais (CEMRI), Universidade Aberta. E-mail: fatimaa@uab.pt

\section{Resumo/abstract/résumé/resumen}

A experiência subjetiva com a doença mental: o caso da depressão

Em Portugal há poucos estudos sobre a experiência com a doença mental, sobretudo sobre a forma como aqueles que a vivenciam no seu quotidiano a experienciam e com ela convivem quotidianamente. Neste artigo, que se baseia em evidência 
empírica resultante de um estudo exploratório apoiado em entrevistas em profundidade junto de dez pessoas com diagnóstico psiquiátrico de depressão crónica, onde se analisam as conceções sobre a sua própria doença e a perceção sobre os impactos na vida quotidiana, procuram-se os sentidos que se tecem a partir dessas experiências pessoais no quotidiano, dando especial ênfase às conceções e representações sobre a sua própria doença, evidenciando as tensões entre a "normalidade" (passado) e a experimentação subjetiva do novo "eu" (identidade atual).

Palavras-chave sociologia da saúde, doença mental, depressão crónica, metodologias qualitativas.

\section{Subjective experience with mental illness: the case of depression}

There have been few studies in Portugal on experience with mental illness, and above all on the way in which those who live with it in their daily lives experience and co-exist with in on a day-to-day basis. This article is based on empiric evidence from an exploratory study supported by in-depth interviews of ten people with a psychiatric diagnosis of chronic depression, in which the interviewees analyse concepts about their own illness and their perceptions of their impacts in daily life. The authors look for meanings that can be pieced together from these daily personal experiences, with special emphasis on the interviewees' concepts about and representations of their own illness, highlighting the tensions between "normality" (past) and the subjective experience of the new "I" (current identity).

$\underline{\text { Keywords }}$ sociology of health, mental illness, chronic depression, qualitative methodologies.

\section{L'expérience subjective de la maladie mentale: le cas de la dépression}

Au Portugal, il y a peu d'études sur l'expérience de la maladie mentale, surtout sur la façon dont la perçoivent ceux qui la vivent au quotidien. Cet article, qui se base sur les résultats empiriques d'une étude exploratoire menée au moyen d'entretiens approfondis auprès de dix personnes ayant un diagnostic psychiatrique de dépression chronique, où sont analysées les conceptions sur leur propre maladie et la perception des impacts sur leur vie quotidienne, recherche les sens qui se tissent à partir de ces expériences personnelles au quotidien, en mettant l'accent sur les conceptions et les représentations de la maladie elle-même, pour souligner les tensions entre la "normalité" (passé) et l'expérimentation subjective du nouveau "moi" (identité actuelle).

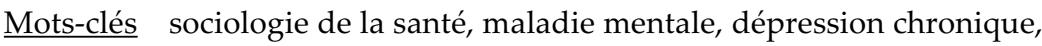
méthodologies qualitatives. 
La experiencia subjetiva con la enfermedad mental: el caso de la depresión

En Portugal hay pocos estudios sobre la experiencia con la enfermedad mental, sobretodo en la manera como la viven día a día aquellos que la padecen. En este artículo, basado en evidencia empírica resultante de un estudio exploratorio apoyado en entrevistas en profundidad a diez personas con diagnóstico psiquiátrico de depresión crónica, donde se analizan las concepciones sobre su propia enfermedad y la percepción sobre los impactos en la vida cotidiana, se procuran los sentidos que se tejen a partir de esas experiencias personales en la vida cotidiana, dando especial énfasis a las concepciones y representaciones sobre su propia enfermedad, evidenciando las tensiones entre la "normalidad" (pasado) y la experimentación subjetiva del nuevo "yo" (identidad actual).

Palabras-clave sociología de la salud, enfermedad mental, depresión crónica, metodologías cualitativas. 